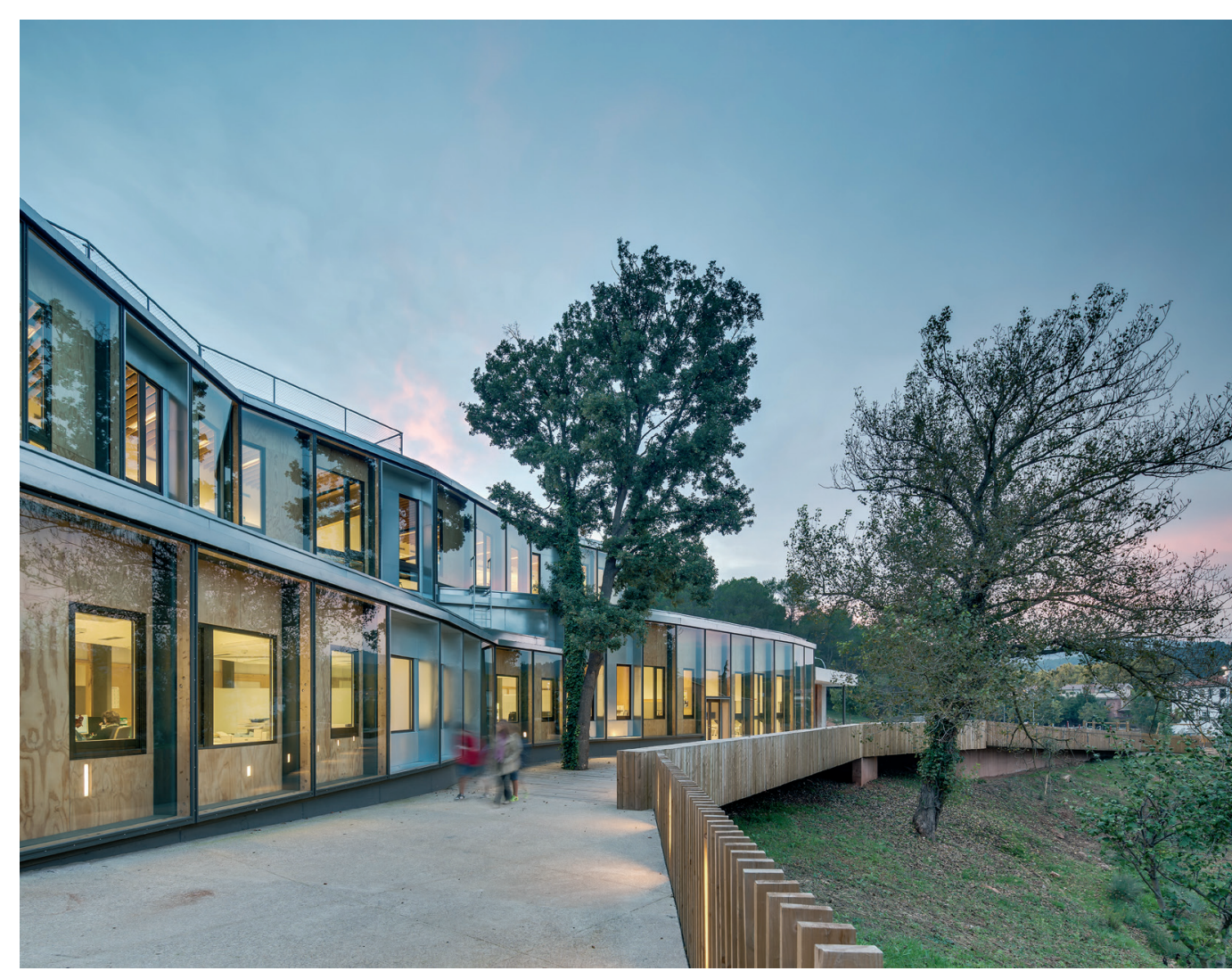

FOTOGRAFIES: Pol Viladoms

\title{
Centre Cívic El Roure i Biblioteca La Ginesta
}

\section{Calderon- Folch- Sarsanedas}

DOI: 10.5821/palimpsesto.12.3927

El Centre Cívic El Roure i Biblioteca La Ginesta és un equipament cultural mixt que engloba un centre cívic amb teatre polivalent una biblioteca municipal fruit d'un procés de treball comú entre tècnics, administració i ciutadans. Plenament integrat al seu entorn el centre és un catalizador social i cultural que revabra un espainatural amb la recuperació paisatgistiun espai natural ann la rocuperació paisatgistide roure martinenc que dona nom al centre.

Begues, un municipi situat al parc natural de Garraf, requeria una biblioteca, un centre cívic i un teatre polivalent. Per dur a terme el projecte, en el que participen diverses entitats locals i intervenen tres administracions diferents, es disposava d'un solar triangular que voreja la Riera Fonda de Begues.

El procés de disseny ha cristal.litzat una cadena de sinèrgies entre entitats, administracions, tècnics, ciutadans i el propi lloc, que va començar amb la definició d'un programa funcional adequat i consensuat i ha culminat amb l'elecció del nom per part dels Beguetans i el procés de catalogació, pel seu valor cultural, d'un roure martinenc.

Dues idees principals vertebren la concepció d'aquest nou equipament: generar una "plaça interior" de confluència i sintonitzar amb l'entorn revitalitzant la Riera.

\section{La "plaça interior"}

El projecte planteja un sol edifici que aglutina els tres serveis, generant un espai comunitari un punt de trobada col.lectiu, que potenciarà la interacció ciutadana, la sinergia cultural i la sostenibilitat en la seva construcció i gestió. L'arquitectura que allotgi un equipament d'aquest tipus ha de ser diversa i pluricèntrica per poder donar suport a la gran varietat d'usuaris i d'activitats previstes però alhora, ha de tenir la capacitat d'enfortir i harmonitzar la relació entre les entitats i els usuaris. El projecte arquitectònic comença amb la definició d'un nucli fundacional, una àgora capaç d'atraure i articular al seu voltant tots els espais definits al programa funcional, un lloc amb el que tots els usuaris s'hi identifiquin.
Sintonitzar amb l'entorn revitalitzant La Riera

El solar, de geometria triangular, es troba a la falda d'un turó cobert de pins i limitat per l'Avgda. Sitges i el carrer Camp dels Prats en els seus costats menors i per la Riera Fonda en el seu costat major.

L'edifici accepta els límits del solar com a propis i n'ocupa la totalitat per aconseguir una construcció horitzontal integrada en el paisatge de la riora i que pugui allotiar el vestíbu.

El disseny proposa recuperar la riera i el record col-lectiu d'un pèlec (popular indret d'esbarjo estiuenc). Per aquesta raó, la façana principal s'orienta a nord, recollint el flux de veïns provinents del camí Ral i revalorant aquest paisatge oblidat, revitalitzant el seu ecosistema i potenciant-ne una nova relació amb els usuaris del centre.

Tant és així, que l'edifici vol ser riera, meandre, pèlec i fluir i reflectir l'entorn. El perfil de geometria orgànica de la façana respon a la reverberació de la sinuositat del meandre i permet generar un nou passeig d'accés i abraçar el roure que dóna nom al Centre; la seva la materialitat és de vegades especular (per reflectir i multiplicar el paisatge en cada fragment de vidre) i de vegades biosfèrica (per respectar la naturalitat de l'entorn).

A l'interior, cada part del programa troba el seu lloc natural, respectant la lògica hidràulica per la qual erosió i sediments van definint el marge de la riba de la riera. D'aquesta manera, l'interior s'organitza en estrats longitudinals resseguint igualment el traçat de la riera i donant lloc a espais més o menys dilatats, de materialitat progressiva més dinàmica, fluida, diàfana i aquosa prop de la façana de la riera i més solida, opaca, privada o pètria en la façana de muntanya. La biblioteca principalment però també l'Espai Nou, el Punt Jove i el bar es desenvolupen al llarg d'aquesta façana oberta al paisatge que ofereix magnifiques situacions de contemplació. El teatre, els bucs d'ascig i diversos senvis de caràcter més d'assaig i diversos servis de caracter més ancat es troben dipositats en o zona més allunyada de la riera. Tots aquests espais s'articulen gràcies a una àgora que per la seva morfologia, materialitat i il.luminació natural procura una atmosfera de naturalitat que recorda la que hem gaudit en recórrer la riera.
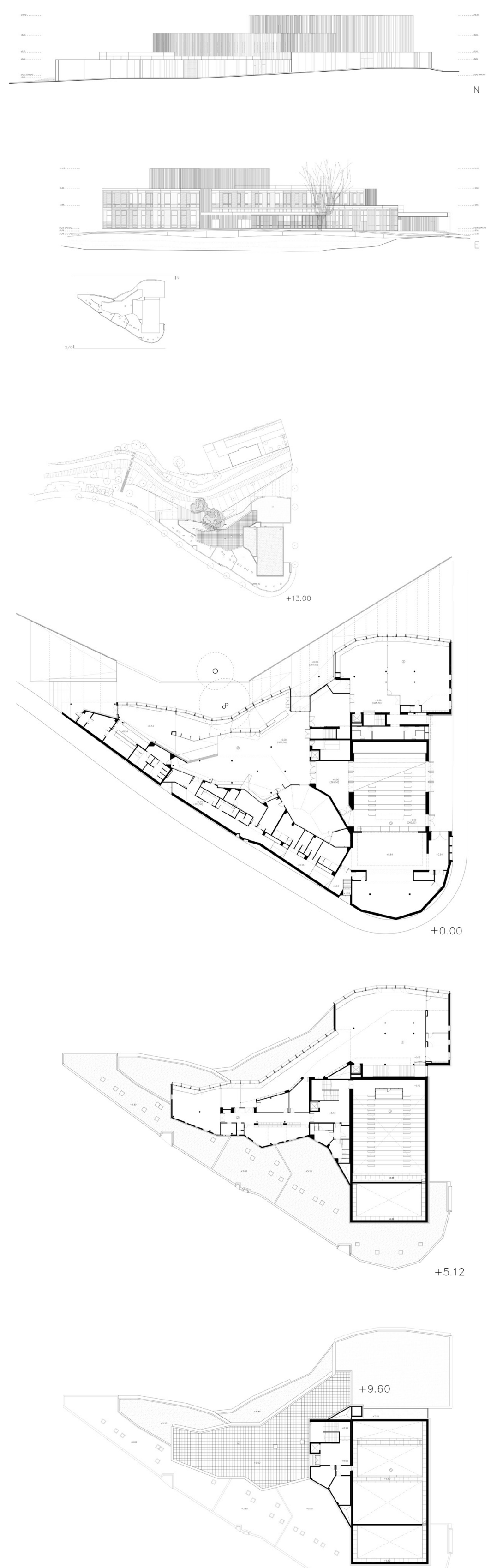

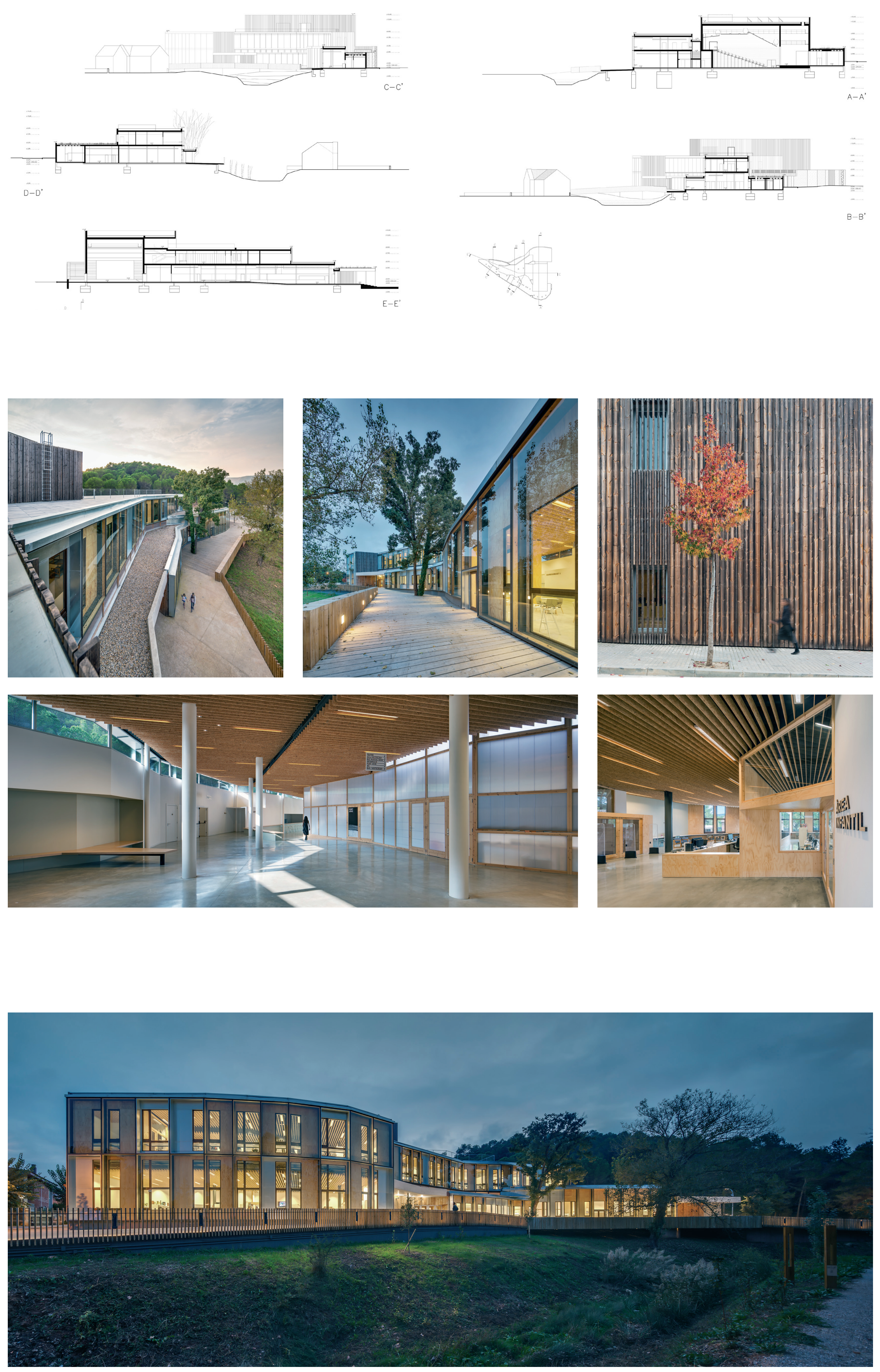